\title{
Observing relationships between lightning and cloud profiles by means of a satellite-borne cloud radar
}

\author{
Martina Buiat $^{1}$, Federico Porcù ${ }^{2}$, and Stefano Dietrich ${ }^{3}$ \\ ${ }^{1}$ University of Ferrara, Dept. of Physics and Earth Sciences, Ferrara, Italy \\ ${ }^{2}$ University of Bologna, Dept. of Physics and Astronomy, Bologna, Italy \\ ${ }^{3}$ Institute of Atmospheric Sciences and Climate (ISAC), National Research Council of Italy (CNR), Rome, Italy \\ Correspondence to: Federico Porcù (federico.porcu@unibo.it)
}

Received: 20 April 2016 - Published in Atmos. Meas. Tech. Discuss.: 28 April 2016

Revised: 9 November 2016 - Accepted: 22 December 2016 - Published: 18 January 2017

\begin{abstract}
Cloud electrification and related lightning activity in thunderstorms have their origin in the charge separation and resulting distribution of charged iced particles within the cloud. So far, the ice distribution within convective clouds has been investigated mainly by means of ground-based meteorological radars. In this paper we show how the products from Cloud Profiling Radar (CPR) on board CloudSat, a polar satellite of NASA's Earth System Science Pathfinder (ESSP), can be used to obtain information from space on the vertical distribution of ice particles and ice content and relate them to the lightning activity. The analysis has been carried out, focusing on 12 convective events over Italy that crossed CloudSat overpasses during significant lightning activity. The CPR products considered here are the vertical profiles of cloud ice water content (IWC) and the effective radius (ER) of ice particles, which are compared with the number of strokes as measured by a ground lightning network (LINET). Results show a strong correlation between the number of strokes and the vertical distribution of ice particles as depicted by the $94 \mathrm{GHz}$ CPR products: in particular, cloud upper and middle levels, high IWC content and relatively high ER seem to be favourable contributory causes for CG (cloud to ground) stroke occurrence.
\end{abstract}

\section{Introduction}

Lightning is an effect of cloud electrification, but there is no consensus in the scientific community on the relative importance of the different mechanisms that cause the charge separation in clouds (MacGorman and Rust, 1998; Sherwood et al., 2006). However, the importance of cloud microphysical structure, in particular the ice water content, in this process is generally accepted and is confirmed by experimental studies and numerical modelling. Considering the various mechanisms, the non-inductive ice-ice interaction is the most efficient process for cloud electrification (Mansell et al., 2005). This mechanism requires the presence of large ice hydrometeors (i.e. graupel or hail pellets) that collide with ice crystals in a suspension of supercooled water droplets (Reynolds et al., 1957; Takahashi, 1978; Berdeklis and List, 2001; Adamo et al., 2007). Laboratory studies by Takahashi (1978) and Jayaratne et al. (1983) also showed that the charge sign is positive or negative as a function of the cloud temperature and liquid water content (LWC). Further laboratory studies have investigated the impact of cloud conditions on electrification (see Saunders et al., 2006), which also underline the importance of mixing solid and liquid hydrometeors. Observational studies indicate that positive cloud-to-ground $(+\mathrm{CG})$ generally occur when the wind regimes increase in the storm evolution (MacGorman and Burgess, 1994), while the hail portion of a storm (Liu et al., 2009) and the tornado sightings in tornadic storms (Carey and Rutledge, 1998) are a couple of examples in which the intensification of the event is coupled with the shift from -CG to +CG (MacGorman and Burgess, 1994).

Actually, a large part of electrification should be the result of colliding ice particles. Even if the mechanisms of electrification are still largely debated, it is agreed that the convective updraught plays a key role, by increasing the liquid water content, the number of supercooled water droplets and the number and size of ice crystals available in the so- 
called charging zone, namely the region in which the charge transfer takes place. After collisions between rimed particles and smaller ice particles, the larger particles take one charge while the smaller ice crystals take the opposite charge. Larger particles such as hail and graupel remain suspended in the updraught and fall out when their terminal velocity exceeds the updraught, while the lighter ice particles are lifted to the upper regions of the cloud, establishing an electric field within the cloud. This generates the in-cloud electric field distribution that initiates lightning when the field exceeds values of $100-250 \mathrm{kV} \mathrm{m}^{-1}$ (Marshall et al., 1995a, b). This is the foundation for numerical models like the 1-D Explicit Microphysics Thunderstorm Model (Solomon and Baker, 1996; Solomon et al., 2005) used to study the relationships between lightning activity and cloud microphysical structure (Formenton et al., 2013).

Since the relationship between lightning and microphysical cloud structure is widely accepted, meteorological radar has frequently been used to investigate thunderclouds. Much research (since Kinzer, 1974) has been devoted to the observation of radar reflectivity and lightning considering the horizontal structure of the thundercloud. Rutledge and Petersen (1994) confirmed with their observations the bipolar model described by Orville et al. (1988): the majority of the negative CG flashes are located in the region of higher radar reflectivity while the positive ones are found in areas of weaker reflectivity, in coincidence with the stratiform rainfall region. Moreover, the number of cloud-to-ground flashes is highly correlated with the vertical radar profile, showing the contribution of the mixed-phase region to the non-inductive charging mechanism. Zipser and Lutz (1994) analysed the vertical profiles of radar reflectivity and the known differences in lightning frequencies for three different regimes (oceanic, monsoon and continental), confirming the relationship between the ice water content (IWC) and the effectiveness of charge separation.

More recently, Katsanos et al. (2007) observed the correlation between reflectivity and lightning, finding a vertical profile with values greater than $53 \mathrm{dBZ}$ in the low levels, of $\approx 45 \mathrm{dBZ}$ at $5 \mathrm{~km}$ and $40 \mathrm{dBZ}$ at $7 \mathrm{~km}$ associated with an $80 \%$ probability of lightning occurrence. Deierling and Petersen (2008) and Deierling et al. (2008) used a Doppler and dual-polarimetric radar as a source of information of ice distribution and updraughts in clouds, in conjunction with lightning data collected in northern Alabama and Colorado/Kansas during two field campaigns. They found significant relationships between the total lightning activity and precipitating and non-precipitating ice mass and estimated fluxes, as well as with updraught volume in the charging zone (i.e. for temperatures colder than $-5^{\circ} \mathrm{C}$ ), and found that these relationships are relatively invariant between different climate conditions. Roberto et al. (2016) found a marked relationship between cloud graupel content by using C-band radar.
Radar reflectivity gradient is also a good indicator for strong updraughts (Zipser and Lutz, 1994; Hondl and Eilts, 1994), which contribute to the creation of opposite charge regions. Some clues in the same direction came also from satellite measurements. Petersen et al. (2005) pointed out that a solid relationship can be found between lightning and cloud ice content. In their study, they used the ice water path (IWP) integrated from cloud top to the $-10^{\circ} \mathrm{C}$ level, as obtained from the Precipitation Radar (PR) on board the Tropical Rainfall Measuring Mission (TRMM) spacecraft (2A25 PR product) to find global relationships between ice water content and lightning activity as observed by the LIS instrument on board the TRMM. They found that on a global scale the relationship between columnar precipitation ice mass and lightning flash density is invariant between land, ocean and coastal regimes (in contrast to rainfall).

However, PR uses a frequency $(13.8 \mathrm{GHz})$ that is not optimal for taking into account the contribution to the IWC due to small ice crystals in the upper cloud portion, which is due to its relatively high sensitivity threshold $(17 \mathrm{dBz})$. This information can instead be provided by the so-called cloud radars, which are active sensors at higher frequency, with much higher sensitivity. Ground-based cloud radars generally provide a limited amount of information about the ice in convective clouds due to the signal attenuation caused by the underlying liquid particles and rain layers. On the contrary, satellite-based cloud radars like the $94 \mathrm{GHz}$ Cloud Profiling Radar (CPR) on CloudSat, and planned on upcoming EarthCARE, have demonstrated their full potential in profiling IWC and ER in the upper cloud layers, where attenuation due to small, solid hydrometeors can be assumed negligible (Stephens et al., 2008; Austin et al., 2009).

In this work, we propose a novel approach for studying the relationship between lightning and the vertical distribution of IWC and ER, characterizing the charged cloud regions. We report and discuss the results obtained by selecting 12 convective events over Italy. Section 2 describes the CPR products used in this study and the LINET sensor data, while in Sect. 3 one storm, optimally observed by CPR, is analysed in detail to extract the cloud structure characteristics favourable to lightning production and to better focus the statistical analysis of the 12 events, described in Sect. 4. In Sect. 5 we summarize and discuss the results.

\section{Instruments and data}

\subsection{CloudSat CPR}

CloudSat is a NASA Earth Sciences Systems Pathfinder mission that started in 2006 and flies in formation with other Earth Sciences missions, taking part in a constellation of sun-synchronous satellites called "A-train" (Stephens et al., 2008). The overlap between the fields of view of the satellites leads to a multi-satellite observing system for studying dif- 
ferent aspects of the atmosphere. In particular, the objective of CloudSat is to measure, for the first time, the vertical structure of the clouds in order to improve their characterization in global models. The CloudSat instrument is the $94 \mathrm{GHz}$ nadirpointing CPR, which measures the power backscattered by targets as a function of distance from the radar. The CPR provides 2-D atmospheric slices with a vertical resolution of $240 \mathrm{~m}$, a $1.7 \times 1.4 \mathrm{~km}$ footprint, and a sensitivity around $-28 \mathrm{~dB}$. The $3 \mathrm{~mm}$ wavelength provides sensitivity to light precipitation and both solid and liquid cloud particles, usually not detected by ground-based low-frequency weather radars (Stephens et al., 2008).

For this study, we used two 2B-level CloudSat products: the cloud geometrical profile (2B-GEOPROF) and the radaronly version of the cloud ice and liquid water content (2BCWC-RO). The 2B-GEOPROF contains the measured reflectivity of the vertical column, after a screening performed with the MODIS cloud mask to filter out non-cloudy profiles and a correction for gaseous absorption. The 2B-CWC-RO provides vertical profiles of IWC, LWC and cloud particle effective radius: the retrieval algorithms work on profiles already classified as cloudy and assume log-normal cloud particles size distribution, also using the vertical temperature profile as estimated by ECMWF analysis (Stephens et al., 2008). Other CloudSat products (i.e. 2B-CWC-RVOD and 2C-ICE) use synergies with other space-borne instruments to provide more accurate IWC and ER estimates, but their availability is limited to the 2006-2011 time frame, due to spacecraft orbit modifications. We preferred to use nominally less accurate products, but considered a longer time record.

Radiation at $94 \mathrm{GHz}$ is strongly attenuated by the interaction with hydrometeors, especially large ice and liquid/melting particles. Experimental data reported average two-way attenuation rates of $4.8 \mathrm{~dB} \mathrm{~km}^{-1}$ for precipitation layers. In low-IWC ice clouds (with $Z_{e}<20 \mathrm{dBZ}$ ), the twoway attenuation rate decreases to $0.38 \mathrm{~dB} \mathrm{~km}^{-1}$, while large ice particles, such as the ones found in the inner layers of convective clouds, are expected to have higher attenuation rates ( $\mathrm{Li}$ et al., 2001). Other uncertainties originate from multiple scattering (Battaglia et al., 2007) and gaseous absorption (from $\mathrm{H}_{2} \mathrm{O}$ and $\mathrm{O}_{2}$ ), and are expected to be significant below $8 \mathrm{~km}$ a.s.l. These sources of uncertainties make it difficult to compare the retrieved microphysical parameters with data from other instruments/algorithms and the definition of the accuracy of the products. Intercomparison studies show discrepancies among parameters retrieved from different sources, depending on the cloud structure (de Boer et al., 2008; Austin et al., 2009; Protat et al., 2010). The CPR is the preferred instrument to obtain quantitative retrieval of microphysical parameters in low-IWC clouds, but is also able to provide information on thicker clouds, with expected lower accuracy.

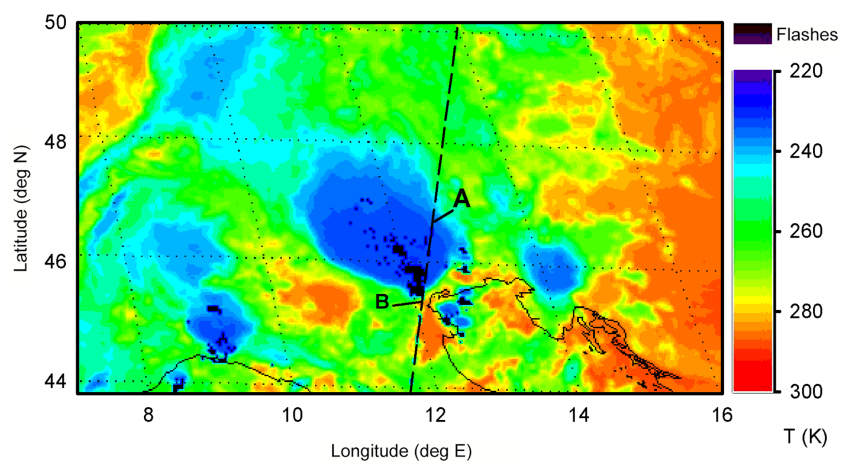

Figure 1. The $10.8 \mu \mathrm{m}$ METEOSAT SEVIRI image at 01:27 UTC on 13 August 2010 centred on the analysed cloud system. Dashed line indicates the track of CloudSat orbit, A and B indicate the beginning and the end of the vertical cross section detailed in Fig. 2.

\subsection{Lightning location system data}

Lightning strokes acquired by LINET (Betz et al., 2007, 2009) have been used in the study. LINET is a lightning detection network developed at the University of Munich in 2006 and consists of about 130 sensors ensuring a 200$250 \mathrm{~km}$ baseline in 17 European countries (Betz and Meneux, 2014).

LINET works in VLF/LF (very low frequency/low frequency) band, but a lightning detection algorithm to discriminate IC from CG is applied as well. Even if CG and IC signals tend to dominate respectively at high and low currents (Betz et al., 2009), a discrimination based on amplitude considerations is not reliable due to their overlap (Betz et al., 2007; Nag and Rakov, 2007). For this reason a 3-D-method called "time of arrival" (TOA) has been developed. This method is based on the different origins of VLF emission between IC and CG: the corresponding differences in travel times are calculated by the TOA locating algorithm and give the height of the lightning emission. TOA requires a maximum sensor baseline of $250 \mathrm{~km}$ and location accuracy sufficient to appreciate the difference between the two travel distances. The location accuracy has been verified by strikes into towers of known position (Betz et al., 2009) and reaches an average accuracy around $150 \mathrm{~m}$. The comparison with other lightning networks has revealed a good time coincidence (Loboda et al., 2009) and a higher capacity to discriminate IC from CG (Lagouvardos et al., 2009). The good sensitivity of the antenna, which detects signals smaller than $5 \mathrm{kA}$, attributes a total lightning quality to the network. The magnetic flux of the lightning signal is detected by means of two orthogonal loops directly as a function of time in a frequency range between 1 and $200 \mathrm{kHz}$, while a GPS clock achieves the signal timing with accuracy better than $100 \mathrm{~ns}$ (Betz et al., 2009). This characteristic is useful for a variety of research purposes, such as cell tracking (Betz et al., 2008), recognition of severe weather conditions (Casella et al., 2012) and the 


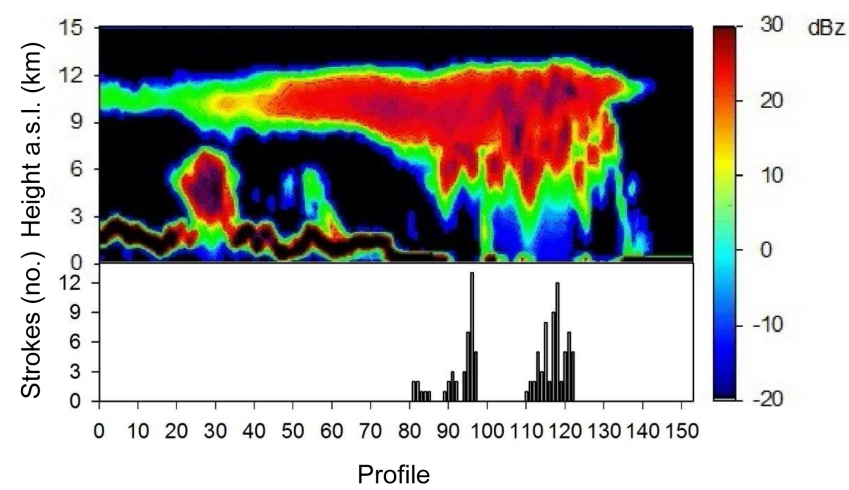

Figure 2. Vertical cross section of the CPR reflectivity along the path shown in Fig. 1. In the bottom panel, the number of CG strokes recorded by LINET for each CPR profile are reported.

study of lightning induced chemical processes (Tuck, 1976), and it guarantees an input for the improvement of models which describe convective processes. The algorithm analyses a window of $512 \mu$ s; i.e. no more than one event can be detected within this time period. Signals of technical origin are discriminated through a fast Fourier analysis (Betz et al., 2007).

\section{Method description - the case study occurred on 12-13 August 2010}

In this Section we present one of the 12 case studies as an example, to make the reader acquainted with the information that the instruments and data described in the previous section can provide if optimally observed by CPR. For this purpose, we selected one mesoscale-organized, longlasting convective system that occurred in northern Italy on the night between 12 and 13 August 2010. The convective episode started in the late afternoon (LT) of 12 August above the western Po Valley and moved eastward in the following hours, reaching the maximum development around 23:30 UTC the same day. This event produced a long time record in terms of the number of strokes in northern Italy.

Figure 1 shows the METOSAT- $910.8 \mu \mathrm{m}$ image at 01:27 UTC in colour shades, with superimposed (in black) pixels where lightning activity was registered by the LINET network within a $10 \mathrm{~min}$ interval centred on the image acquisition time. The dashed black line indicates the track of the CloudSat orbit that overpasses the area of interest at 01:29 UTC. The portion of the CloudSat orbit from A to B provided the CPR profiles included in the data set for this case. The case was selected because the orbit is very close to the electrically active portion of the cloud, and because when sampling the anvil region, no strokes were detected by LINET during the specific 10 min interval.

In Fig. 2, the CPR reflectivity is plotted in colour shades along the path shown in Fig. 1, while the bars below indicate
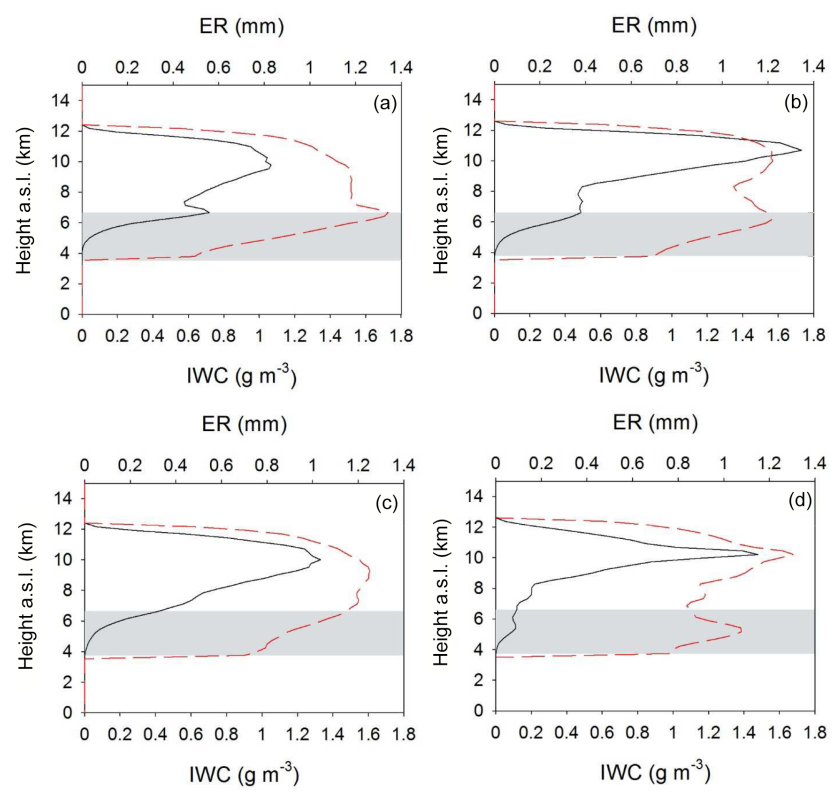

Figure 3. Vertical profiles of IWC (black line, bottom axis) and ER (red line, top axis) for four CPR profiles, namely (a) no. 96 (13 strokes), (b) no. 118 (12 strokes), (c) no. 106, and (d) no. 124 (zero strokes). The grey band indicates the mixed-phase layer, where $-20^{\circ}<T<0^{\circ}$.

the number of CG strokes registered by LINET for each corresponding CPR profile. For each cloud profile, a neighbourhood of $1.5 \mathrm{~km}$ radius is searched for strokes in the LINET database, within an interval of $\pm 5 \mathrm{~min}$ around the time of the satellite overpass. The structure of the cloud shows a welldeveloped anvil stretching to the north and the convective activity to the south. A thick, highly reflective cloud ice layer is present: the top of the cloud reaches $12 \mathrm{~km}$ a.s.l., while high ice water content (above $0.8 \mathrm{~g} \mathrm{~m}^{-3}$, not shown) columns reach $5 \mathrm{~km}$ a.s.l. It has to be remarked that the CPR signal could be strongly attenuated by large hydrometeors and thus CPR profiles are expected to not properly describe the lower cloud layers and rain structures.

Lightning activity occurs only on the convective part of the cloud, while no strokes are detected on the anvil or in the growing convective cell at around profile no. 30 along the track. However, there is a relatively large region (between profile no. 98 and profile no. 110) where no strokes are recorded despite the CPR reflectivity showing a thick cloud layer. This suggests that not only is the high ice content a key factor in developing strokes, but also that the vertical distribution of IWC has an impact. Out of the total number of strokes detected (82), only three are positive, and they are detected in the area of weakest reflectivity, which corresponds to the stratiform rainfall region, confirming the model described by Orville (Orville et al., 1988).

To better understand the role of IWC vertical distribution, a more detailed analysis is made by selecting profiles with 

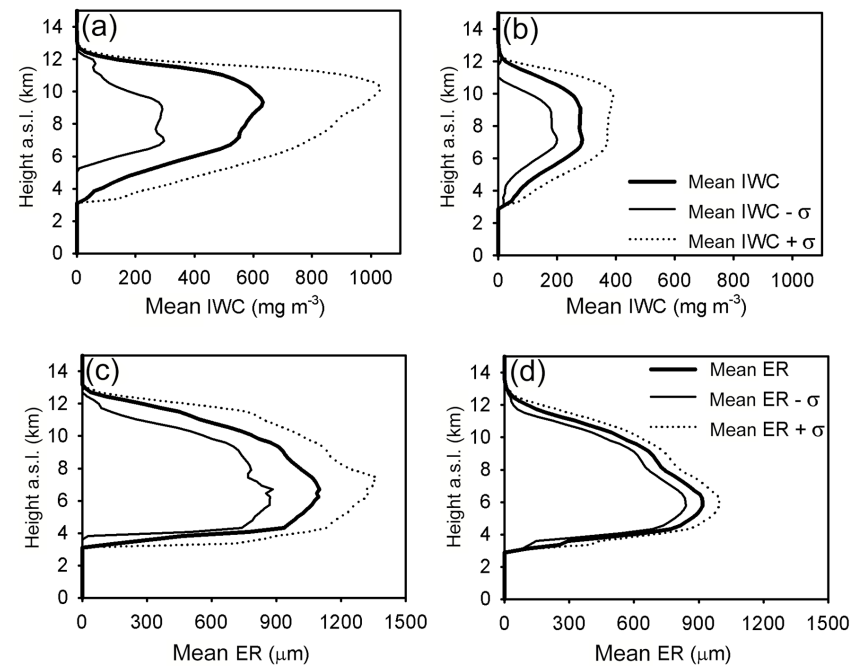

Figure 4. (a) IWC vertical profiles with CG strokes; (b) same quantity without CG strokes; (c) ER vertical profiles with CG strokes; (d) same quantity without CG strokes.

and without lightning and in the convective part of the cloud. In Fig. 3, the vertical profiles of CPR products IWC and ER are presented in case of lightning detected (top panel) and no lightning detected (bottom panel) within the profiles. Figure 3a shows the profile no. 96 from the start of the cross section reported in Fig. 2, where the LINET registered 13 strokes, while 12 strokes are reported for the profile no. 118, shown in Fig. 3b. For Fig. 3c (profile no. 106) and $3 \mathrm{~d}$ (profile no. 124), still in the active part of the cloud, no strokes are reported. The cloud structures in these four profiles present some similarities: a thick ice layer between 5 and $11 \mathrm{~km}$ above the ground with peak concentration larger than $1 \mathrm{~g} \mathrm{~m}^{-3}$ at about $10 \mathrm{~km}$ above the ground. The vertical distribution of ice content seems to be more related to the cloud capability of producing strokes: for no lightning cases the ice content decreases monotonically below the concentration peak until it vanishes, reaching the melting layer (estimated around $3.7 \mathrm{~km}$ a.s.l.). In case of strokes, the IWC structure presents a secondary concentration peak at about 6.5$7 \mathrm{~km}$ a.s.l., at the same height where a peak of ER is present, just above the mixed-phase layer, indicated by the grey band in Fig. 3, suggesting the possible presence of graupel.

For this case, the presence of lightning is favoured by a dense ice layer at the cloud top, where relatively smaller ice particles are present, coupled with a second layer of high IWC, characterized by larger hydrometeors that, given the known structure of thunderstorm, can be identified as large graupel. This structure is coherent with the graupel-crystal charging mechanism.
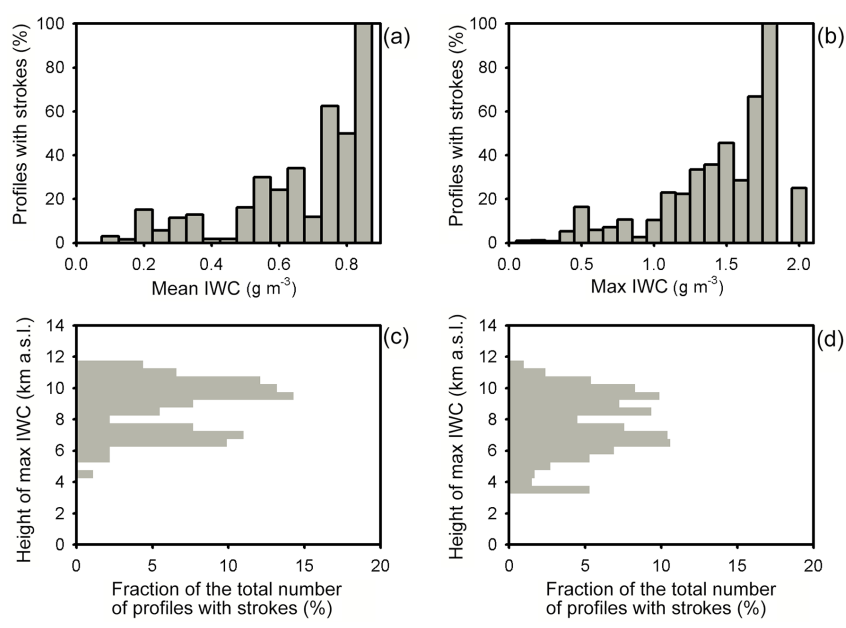

Figure 5. (a) Fraction of profiles with at least one stroke as a function of the mean IWC of the profile; (b) same quantity distributed according to the maximum value of the IWC along the profile; fraction of profiles with at least one stroke (c), and without strokes (d) divided by the total number of profiles according the height of the maximum IWC.

\section{Statistical relationship between cloud structure and lightning over Italy}

Lucky CloudSat overpasses over storms, like the one described in the previous section, are not common. This is mainly due to the narrow observation of CPR, coupled with the low Earth-orbiting satellite sampling. However, we attempt to extend the statistics by collecting other significant storms over Italy and sufficiently sampled by at least one CloudSat overpass in their core convective structure. We limited our research to five convective seasons starting from 2009, when the LINET sensors network reached the baseline necessary for optimal lightning detection, also in Italy. In this way we found 12 case studies in this period with the necessary characteristics. Each of them was analysed in detail, similarly to what shown in the previous section. In the 12 cases, we counted a total of $301 \mathrm{CG}$ strokes assigned to 97 profiles, out of a total of 1701 cloud profiles collected by CPR. We consider this resulting data set quite representative of the variety of profiles that occurred during the Italian storms in the convective season. Given the limitations of the CPR-retrieved quantities discussed in Sect. 2.1, we will present our results with a caution to only consider the numerical values valid within a CloudSat analysis, performed with the 2B-CWC-RO data product.

An overview of CPR profiles composing the data set is presented in Fig. 4. The mean characteristics of the IWC and ER vertical profiles are plotted, separating the class of profiles with and without CG lightning. Note that we count only CG strokes, since they propagate vertically. IC often propagate horizontally and cannot be directly associated to a single cloud profile, so they have not been included in this study fo- 
cusing on vertical structures. A clear difference between the classes is evident. Not only is the IWC larger, especially in the upper levels (about $10 \mathrm{~km}$ ) where lightning is detected, but ER profiles also evidence an overall increase, especially around 5-6 km.

More hints on the profiles statistical properties are illustrated in Fig. 5. To provide a rough assessment of the probability distribution for the quantities of our interest we adopted the histograms, in which the frequencies of observations occurring in certain ranges of values are shown. In Fig. 5a the histogram of mean IWC for cloud profiles with at least one CG stroke is shown (the histograms of profiles without lightning are simply the complement). A vertical mean IWC value of $0.75 \mathrm{~g} \mathrm{~m}^{-3}$ represents a significant threshold to increase the probability of CG strokes. However, strokes may also occur for very low mean IWC (below $0.2 \mathrm{~g} \mathrm{~m}^{-3}$ ), while, looking at this histogram, the probability of having strokes is $100 \%$ for profiles with mean IWC $>0.85 \mathrm{~g} \mathrm{~m}^{-3}$, keeping in mind that the significance of the mean value along the profile is quantitatively questionable due to the mentioned nonquantifiable effect of attenuation. At some extent, the maximum value of IWC along the profile can be regarded as less affected by attenuation, since the layers above the one with the maximum have lower IWC amounts. The histogram in Fig. $5 \mathrm{~b}$ shows the statistics of maximum value of the IWC measured along the profiles: a maximum IWC of $1 \mathrm{~g} \mathrm{~m}^{-3}$ represents the threshold value where the probability of having CG strokes increases. However, there are profiles with very high maximum IWC, around $2 \mathrm{~g} \mathrm{~m}^{-3}$ without strokes. This is a first signal that the mean and maximum IWC by themselves are not enough to relate the IWC profile to the lightning occurrence. As a matter of fact, the height at which the maximum occur represents an important additional piece of information that we can extract from the data set, exploiting the potential of the CPR's observations. As far as this parameter is concerned, it makes sense to separately plot the histograms describing the statistics of profiles with lightning (5c) and the ones without lightning (5d). Observing those histograms, we can recognize two regions in the vertical structure of the storms. The first one can be referred to as the charging zone; it ranges from about 0 to $-20^{\circ} \mathrm{C}$, which in our convective season data set over Italy are the bars at about $5-7.5 \mathrm{~km}$. The other one is located in the upper cloud layers. This latter zone, depending on the specific profile, can be interested by deep convection, hosting large-sized particles or have large IWC contents due to small and light charged ice crystals. Comparing these two histograms, $5 \mathrm{c}$ evidences the existence of the two regions better than 5d. Furthermore, the peak values of maximum IWC in the upper cloud region are more frequent (longer bars) in 5c. Overall, the distribution shows that the CG strokes occurrence is favoured in profiles with IWC peak located in the upper cloud layers $(68 \%)$. Hence, high IWC values in the upper cloud layers are an important feature of convective profiles and undoubtedly CPR provides information, not easily obtainable from other
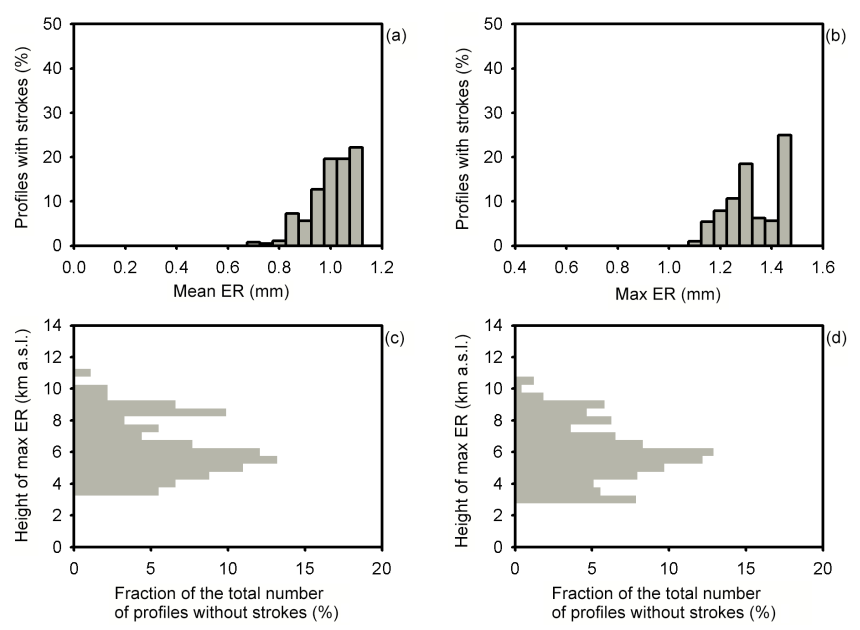

Figure 6. (a) Fraction of profiles with at least one stroke as a function of the mean ER of the profile; (b) same fraction as a function of the maximum effective radius in the profile; fraction of profiles with at least one stroke (c), and without strokes (d) divided by the total number of profiles according the height of the maximum ER.

ground or satellite measurements, to recognize the presence of this feature.

The second CloudSat product we analysed in order to characterize the cloud profiles is the ER of the ice particles, defined as the ratio between third- and second-order moments of the particle size distribution, i.e. the area-weighted mean of the particle radius (Hansen and Travis, 1974). It is worth noting that, when non-spherical ice particles are involved, the particle radius means the radius of the equivalent mass ice sphere. Similarly to what has already been done for IWC, in Fig. 6a and b we show the histograms of mean ER and maximum ER for profiles with at least one CG stroke. A relatively high mean value of ER (greater than $0.85 \mathrm{~mm}$ ) or a high maximum (greater than $1.1 \mathrm{~mm}$ ) seems to be a necessary condition for CG strokes. CPR is not designed to classify hydrometeor types, but large mean or maximum values of ER are compatible with the presence of large ice particles (probably graupel) in a significant part of the cloud profile. Histograms $6 \mathrm{c}$ and $6 \mathrm{~d}$ illustrate where the ER maxima are vertically located. As expected, the region in convective storms where we can generally find the maximum of ER is the charging zone, where the charge separation occurs. However, a significant number of profiles, in this case without a clear statistical preference between profile with and without lightning, have their ER maximum in the upper cloud layers, clue of strong updraught in the profiles that makes the presence of suspended large particles possible.

To further investigate the outcomes of Figs. 5 and 6, for each profile we computed the average values of IWC and ER values along the two vertical regions evidenced, hereafter referred to as the "charging zone" (CZ) 0 to $-20^{\circ} \mathrm{C}$ and "upper cloud" (UC) from -20 and $-40^{\circ} \mathrm{C}$. The panels in Fig. 7 

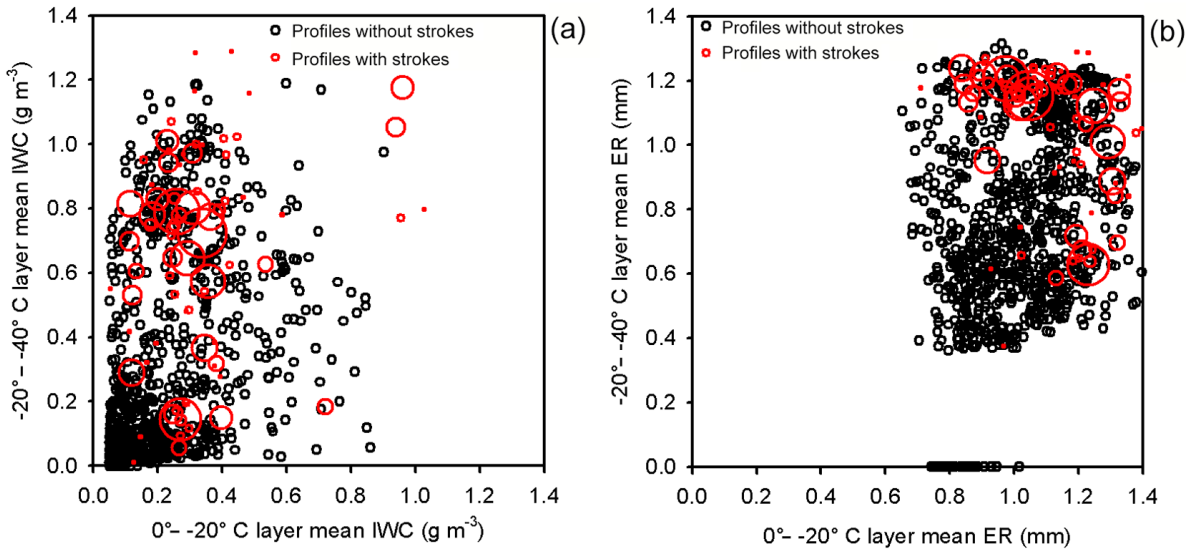

Figure 7. Distribution of profiles with strokes (red circles, with radius proportional to the number of strokes) and without strokes (black circles), with respect to (a) mean IWC in the 0 to -20 and -20 to $-40^{\circ} \mathrm{C}$ cloud layers, and (b) mean ER in the 0 to -20 and -20 to $-40{ }^{\circ} \mathrm{C}$ cloud layers.

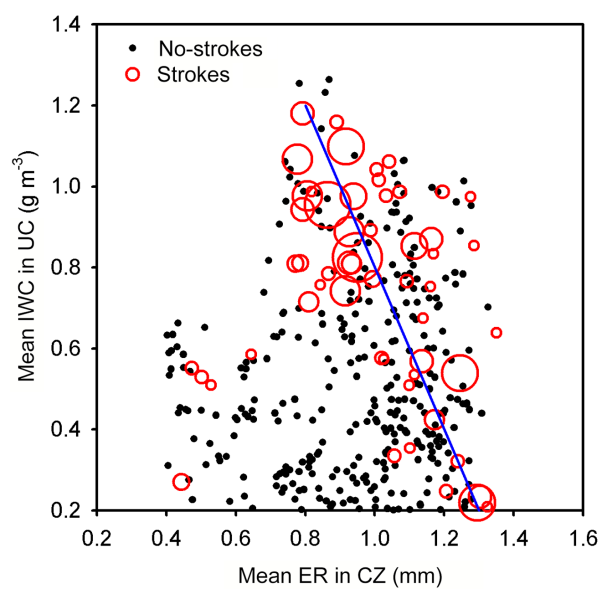

Figure 8. Distribution of profiles with strokes (red circles, with radius proportional to the number of strokes) and without strokes (black circles), with respect to mean IWC in the $-20-40{ }^{\circ} \mathrm{C}$ cloud layers (above $9 \mathrm{~km}$ ) and mean ER in the $0-20{ }^{\circ} \mathrm{C}$. In this case we assume that the profile is entirely composed by ice. The blue line fits the distribution of profiles with strokes.

are the scatter plots of different couples of variables characterizing the profiles. Black circles represent profiles without strokes, while profiles with strokes are red circles with the radius proportional to the number of strokes. Lightning is certainly favoured by high IWC in the UC and relatively high IWC in the CZ level, but a number of profiles with lightning are found also in cases of much lower UC IWC, provided that $\mathrm{CZ}$ average IWC is above $0.2 \mathrm{~g} \mathrm{~m}^{-3}$. Very few points with strokes have very high CZ IWC, corresponding to low IWC in UC.

As for the effective radius, it seems that lightning occurs for any value of UC mean ER in the range $0.4-1.2 \mathrm{~mm}$, while a relatively high value (ER $>0.9 \mathrm{~mm}$ ) of CZ ER is needed to have lightning.

To fully understand the meaning of the numerical values reported (especially of IWC), it has to be clarified how IWC is computed by $2 \mathrm{~B}-\mathrm{CWC}-\mathrm{RO}$ within the melting layer, including in the $\mathrm{CZ}$ layers in our scheme. The IWC is computed assuming the entire profile is ice and its value is set to zero in the portion of the profile with temperatures lower than the freezing level, as estimated by ECMWF analysis. Then, in the region between -20 and $0^{\circ}$, the IWC (where it is assumed a mixture of ice and liquid) is linearly scaled with temperature, from its value at the level $T=-20^{\circ}$ to zero at $T=0^{\circ}$. The ER is computed as if the entire profile is ice and set to zero for the cloud layers below $T=0$.

\section{Conclusions}

From in-depth analysis of the 12-13 August 2010 case study, we have identified two distinct regions in the vertical cloud structure that are significant for lightning production. The uppermost region, found for Italy at an altitude of about $10 \mathrm{~km}$ a.s.l., is characterized by high values of IWC (above $1 \mathrm{~g} \mathrm{~m}^{-3}$ ), with ER below $1 \mathrm{~mm}$. The second region is characterized by a secondary IWC peak around $7 \mathrm{~km}$ a.s.l. In this layer the cloud particles effective radius reaches the maximum, indicating the presence of larger ice hydrometeors. The profiles with no-lightning usually do not show this secondary peak in IWC, even if a peak in ER is found around $7 \mathrm{~km}$ a.s.l. These structures have a correspondence in the dipole description of non-inductive electrification through particle-particle collisions: the ice crystals, positively charged, are pushed upward by the updraught, while the larger hydrometeors, negatively charged, are maintained in the lower part of the cloud. While looking for a statistical confirmation we have extended the analysis to a data set of $1701 \mathrm{CPR}$ vertical profiles from 
12 storms over Italy since 2009 . The statistical analysis show that a high mean and maximum IWC content is required to have strokes, possibly with peaks at around $7 \mathrm{~km}$ (Katsanos et al., 2007) or $10 \mathrm{~km}$, while large values of profile-averaged ER also favour stroke production, as well as large ice particles just above the mixed-phase cloud layers (ER $>0.9 \mathrm{~mm}$ ).

Despite the difficulties in picking out CloudSat overpasses intersecting active convective cells over Italy, the combined use of CG lightning data and the profiles of IWC and ER provided by the CPR for the data set has substantially confirmed the case study findings concerning the vertical distribution of IWC and ER necessary for lightning. We can resume as follows:

1. Statistically, the IWC UC has demonstrated its importance for describing lightning occurrences. High IWC values can be caused by strong on-going updraughts or the results of long-lasting cumulative effects of small charged ice particles, resulting from collisions that occurred in the charging zone and were transported upward to build up a usually positive charged layer. In both cases they favour the presence of CG lightning.

2. A well-known necessary condition for CG lightning occurrence is the presence of a sensible amount (middle to high IWC) of large particles (high ER values) in the $\mathrm{CZ}$. They form the usually negative $\mathrm{CZ}$ layer and their effect on the electric field can be further strengthened for induction by the presence of the UC layer.

3. When the two layers are clearly separated (see Fig. 3b and d), showing two relative maxima, the in-cloud electric field can reach and exceed the high values of 100$250 \mathrm{kV} \mathrm{m}^{-1}$ (Marshall et al., 1995a, b) necessary to generate lightning.

The combined effect of the two layers is evident in Fig. 8, where we chose to connect the UC IWC and the CZ ER in one scatter plot. Apart from a few outliers, the profiles with lightning are distributed around the blue tendency line.

However, the position of the upper cloud layer of charged ice particles with respect to the CZ is also deeply influenced by high-altitude wind regimes, storm rotation, etc. (Stolzenburg et al., 1998). The CPR observation is composed by vertical narrow beams having the effect of slicing the storm. Hence, each beam captures information related only with the microphysics and the electric structure of a part of the whole storm. This is one of the reasons for the observed spreading in the obtained statistics.

Anyway, the best exploitation of CPR data is the singlecase analysis. When, like in Sect. 3, one storm has been sampled enough in its core convective part, we can more easily recognize the different regions of the storm, make a specific interpretation of the signature of the eventual presence of the double layer and verify the presence of corresponding lightning activity.

\section{Data availability}

The CloudSat Standard Data Products used in this work are provided by the CloudSat Data Processing Center and are available after free registration at http://www.cloudsat.cira. colostate.edu/data-products.

LINET data are available from Nowcast GmhB (https: //www.nowcast.de/) after an agreement with the Nowcast GmhB management.

Acknowledgement. CloudSat Standard Data Products are distributed by the CloudSat Data Processing Center, located at the Cooperative Institute for Research in the Atmosphere at Colorado State University in Fort Collins, within the NASA CloudSat Project. LINET data have been provided by Nowcast GmhB (https://www. nowcast.de/) within a scientific agreement between H.-D. Betz and the Satellite Meteorological Group of CNR-ISAC in Rome.

The comments of two anonymous reviewers greatly increased the quality and significance of the paper.

Edited by: G. Vulpiani

Reviewed by: two anonymous referees

\section{References}

Adamo, C., Solomon, R., Medaglia, C. M., Dietrich, S., and Mugnai, A.: Cloud Microphysical Properties from the Remote Sensing of Lightning within the Mediterranean, edited by:: Levizzani, V., Bauer, P., and Turk, J.: Measuring precipitation from space: EURAINSAT and the future, 127-134, Springer, 2007.

Austin, R. T., Heymsfield, A. J., and Stephens, G. L.: Retrieval of ice cloud microphysical parameters using the Cloudsat mmwave radar and temperature, J. Geophys. Res., 114, D00A23, doi:10.1029/2008JD010049, 2009.

Battaglia, A., Ajewole, M. O., and Simmer, C.: Evaluation of radar multiple scattering effects in Cloudsat configuration, Atmos. Chem. Phys., 7, 1719-1730, doi:10.5194/acp-7-1719-2007, 2007.

Berdeklis, P. and List, R.: The ice crystal-graupel collision charging mechanism of thunderstorm electrification, J. Atmos. Sci.,58, 2751-2770, doi:10.1175/1520-0469(2001)058< 2751:TICGCC'2.0.CO;2, 2001.

Betz, H. D. and Meneux, B.: LINET systems - 10 years experience, Proc. of International Conference on Lightning Protection (ICLP), 1553-1557, doi:10.1109/ICLP.2014.6973377, 2014.

Betz, H.-D., Schmidt, K., Fuchs, B., Oettinger, W. P., and Holler, H.: Cloud lightning: Detection and utilization for total-lightning measured in the VLF/LF regime, J. Lightning Res., 2, 1-17, 2007.

Betz, H.-D., Marshall, T. C., Stolzenburg, M., Schmidt, K., Oettinger, W. P., Defer, E., Konarski, J., Laroche P., and Dombai, F.: Detection of in-cloud lightning with VLF/LF and VHF networks for studies of the initial discharge phase, Geophys. Res. Lett., 35, L23802, doi:10.1029/2008GL035820, 2008.

Betz, H.-D., Schmidt, K., Laroche, P., Blanchet, P., Oettinger, W. P., Defer, E., Dziewit, Z., and Konarski, J.: LINET - An inter- 
national lightning detection network in Europe, Atmos. Res., 91, 564-573, doi:10.1016/j.atmosres.2008.06.012, 2009.

Carey, L. D. S. and Rutledge, A.: Electrical and multiparameter radar observations of a severe hailstorm, J. Geophys. Res., 103, 13979-14000, doi:10.1029/97JD02626, 1998.

Casella, D., Dietrich, S., Di Paola, F., Formenton, M., Mugnai, A., Porcù, F., and Sanò, P.: PM-GCD - a combined IR-MW satellite technique for frequent retrieval of heavy precipitation, Nat. Hazards Earth Syst. Sci., 12, 231-240, doi:10.5194/nhess-12-2312012, 2012.

de Boer, G., Tripoli, G. J., and Eloranta, E. W.: Preliminary comparison of CloudSAT-derived microphysical quantities with groundbased measurements for mixed-phase cloud research in the Arctic, J. Geophys. Res., 113, D00A06, doi:10.1029/2008JD010029, 2008.

Deierling, W. and Petersen, W. A.: Total lightning activity as an indicator of updraft characteristics, J. Geophys. Res., 113, D16210, doi:10.1029/2007JD009598, 2008.

Deierling, W., Petersen, W. A., Latham, J., Ellis, S., and Christian, H.: The relationship between lightning activity and ice fluxes in thunderstorms, J. Geophys. Res., 113, D15210, doi:10.1029/2007JD009700, 2007.

Formenton, M., Panegrossi, G., Casella, D., Dietrich, S., Mugnai, A., Sanò, P., Di Paola, F., Betz, H.-D., Price, C., and Yair, Y.: Using a cloud electrification model to study relationships between lightning activity and cloud microphysical structure, Nat. Hazards Earth Syst. Sci., 13, 1085-1104, doi:10.5194/nhess-131085-2013, 2013.

Hansen, J. E and Travis, L. D.: Light scattering in planetary atmospheres, Space Sci. Rev., 16, 527-610, doi:10.1007/BF00168069, 1974.

Hondl, K. D. and Eilts, M. D.: Doppler radar signatures of developing thunderstorms and their potential to indicate the onset of cloud-to-ground lightning, Mon. Weather Rev., 122, 1818-1836, doi:10.1175/1520-0493(1994)122< 1818:DRSODT> 2.0.CO;2, 1994.

Jayaratne, E. R., Saunders, C. P. R., and Hallett, J.: Laboratory studies of the charging of soft hail during ice crystal interactions, Q. J. Roy. Meteorol. Soc., 109, 609-630, doi:10.1002/qj.49710946111, 1983.

Katsanos, D. K., Lagouvardos, K., Kotroni, V., and Argiriou, A. A.: The relationship of lightning activity with microwave brightness temperature and spaceborne radar reflectivity profiles in the central and eastern Mediterranean, J. Appl. Meteorol. Clim., 46, 1901-1912, doi:10.1175/2007JAMC1454.1, 2007.

Kinzer, G. D.: Cloud-to-ground lightning versus radar reflectivity in Oklahoma thunderstorms, J. Atmos. Sci., 31, 787-799, doi:10.1175/1520-0469(1974)031< 0787:CTGLVR> 2.0.CO;2, 1974.

Lagouvardos, K., Kotroni, V., Betz, H.-D., and Schmidt, K.: A comparison of lightning data provided by ZEUS and LINET networks over Western Europe, Nat. Hazards Earth Syst. Sci., 9, 1713-1717, doi:10.5194/nhess-9-1713-2009, 2009.

Li, L., Sekelski, S. M., Reising, S. C., Swift, C. T., Durden S. L., Sadowy, G. A., Dinardo, S. J., Li, F. K., Huffmann, A., Stephens, G., Babb, D. B., and Rosenberger, H. W.: Retrieval of Atmospheric Attenuation Using Combined Ground-Based and Airborne 95-GHz Cloud Radar Measurements, J. Atmos. Ocean. Tech., 18, 1345-1353, 2001.
Liu, D., Feng, G., and Wu, S.: The characteristics of cloud-toground lightning activity in hailstorms over northern China, Atmos. Res., 91, 459-465, doi:10.1016/j.atmosres.2008.06.016, 2009.

Loboda, M., Betz, H.-D., Baransky, P., Wiszniowski, J., and Dziewit, Z.: New Lightning Detection Networks in Poland LINET and LLDN, Atmos. Sci. J., 3, 29-38, 2009.

MacGorman, D. R. and Burgess, D. W.: Positive cloud-to-ground lightning in tornadic storms and hailstorms, Mon. Weather Rev., 122, 1671-1697, doi:10.1175/1520-0493(1994)122< 1671:PCTGLI> 2.0.CO;2, 1994.

MacGorman, D. R. and Rust, W. D.: The electrical nature of storms, Oxford University Press, 1998.

Mansell, E. R., MacGorman, D. R., Ziegler, C. L., and Straka, J. M.: Charge structure and lightning sensitivity in a simulated multicell thunderstorm, J. Geophys. Res., 110, D12101, doi:10.1029/2004JD005287, 2005.

Marshall, T. C., McCarthy, M., and Rust, W. D.: Electric field magnitudes and lightning initiation in thunderstorms, J. Geophys. Res., 100, 7097-7103, doi:10.1029/95JD00020, 1995a.

Marshall, T. C., Rust, W. D., and Stolzenburg, M.: Electric structure and updraft speeds in thunderstorms over the Southern Great Plains, J. Geophys. Res., 100, 1001-1015, doi:10.1029/94JD02607, 1995b.

Nag, A. and Rakov, V. A.: Pulse trains that are characteristic of preliminary breakdown in cloud-to-ground lightning but are not followed by return stroke pulses, J. Geophys. Res., 113, D01102, doi:10.1029/2007JD008489, 2007.

Orville, R. E., Henderson, R. W., and Bosart, L. F.: Bipole patterns revealed by lightning locations in mesoscale storm systems, Geophys. Res. Lett., 15, 129-132, doi:10.1029/GL015i002p00129, 1988.

Petersen, W. A., Christian, H. J., and Rutledge, S. A.: TRMM observations of the global relationship between ice water content and lightning, Geophys. Res. Lett., 32, L14819, doi:10.1029/2005GL023236, 2005.

Protat, A., Delanoë, J., O'Connor, E. J., and L'Ecuyer, T. S.: The Evaluation of CloudSat and CALIPSO Ice Microphysical Products Using Ground-Based Cloud Radar and Lidar Observations, J. Atmos. Ocean. Tech., 27, 793-810, 2010.

Reynolds, S. E., Brook, M., and Gourley, M. F.: Thunderstorm charge separation, J. Meteorol., 14, 426-436, 1957.

Roberto, N., Adirosi, E., Baldini, L., Casella, D., Dietrich, S., Gatlin, P., Panegrossi, G., Petracca, M., Sanò, P., and Tokay, A.: Multi-sensor analysis of convective activity in central Italy during the HyMeX SOP 1.1, Atmos. Meas. Tech., 9, 535-552, doi:10.5194/amt-9-535-2016, 2016.

Rutledge, S. A. and Petersen, W. A.: Vertical radar reflectivity structure and cloud-to-ground lightning in the stratiform region of MCS's: Further evidence for in-situ charging in the stratiform region, Mon. Weather Rev., 122, 1760-1776, doi:10.1175/15200493(1994)122< 1760:VRRSAC> 2.0.CO;2, 1994.

Saunders, C. P. R., Bax-Norman, H., Emersic, C., Avila, E. E., and Castellano, N. E.: Laboratory studies of the effect of cloud conditions on graupel/crystal charge transfer in thunderstorm electrification, Q. J. Roy. Meteorol. Soc., 132, 2653-2673, doi:10.1256/qj.05.218, 2006. 
Sherwood, S. C., Phillips, V. T. J., and Wettlaufer, J. S.: Small ice crystals and the climatology of lightning, Geophys. Res. Lett., 33, L05804, doi:10.1029/2005GL025242, 2006.

Solomon, R. and Baker, M.: A one-dimensional lightning parameterization, J. Geophys. Res., 101, 14983-14990, doi:10.1029/96JD00941, 1996.

Solomon, R., Medaglia, C. M., Adamo, C., Dietrich, S., Mugnai, A., and Biader, U.: An Explicit Microphysics Thunderstorm Model, Int. J. Modell. Simul., 25, 112-118, 2005.

Stephens, G. L., Vane, D. G., Boain, R. J., Mace, G. G., Sassen, K., Wang, Z., Illingworth, A. J., O'Connor, E. J., Rosasaow, W. B., Durden, S. L., Miller, S. D., Austin, R. T., Benedetti, A., and Mitrescu, C.: The Cloudsat mission and the A-Train. A new dimension of space-based observation of clouds and precipitation, B. Am. Meteorol. Soc., 1771-1790, doi:10.1175/BAMS-83-121771, 2002.

Stephens, G. L., Vane, D. G., Tanelli, S., Im, E., Durden, S., Rokey, M., Reinke, D., Partain, P., Mace, G. G., Austin, R., L'Ecuyer, T., Haynes, J., Lebsock, M., Suzuki, K., Waliser, D., Wu, D., Kay, J., Gettelman, A., Wang, Z., and Marchand, R.: CloudSat mission: Performance and early science after the first year of operation, J. Geophys. Res., 113, D00A18, doi:10.1029/2008JD009982, 2008.
Stolzenburg, M., Rust, W. D., and Marshall, T. C.: Electrical structure in thunderstorm convective regions, J. Geophys. Res, 104, 14097-14108, doi:10.1029/97JD03547, 1998.

Takahashi, T.: Riming electrification as a charge generation mechanism in thunderstorms, J. Atmos. Sci., 35, 1536-1548, doi:10.1175/1520-0469(1978)035< 1536:REAACG> 2.0.CO;2, 1978.

Tuck, A. F.: Production of nitrogen oxides by lightning discharges, Q. J. Roy. Meteorol. Soc., 102, 749-755, doi:10.1002/qj.49710243404, 1976.

Zipser, E. and Lutz, K. R.: The vertical profile of radar reflectivity of convective cells: a strong indicator of storm intensity and lightning probability?, Mon. Weather Rev., 122, 1751-1759, doi:10.1175/1520-0493(1994)122< 1751:TVPORR> 2.0.CO;2, 1994. 